\title{
Gastrointestinal bleeding
}

\author{
ALAN E. READ \\ M.D., F.R.C.P.
}

\author{
Professor of Medicine, University of Bristol, Royal Infirmary, Bristol BS2 $8 \mathrm{HW}$
}

\section{Introduction}

It is a very great personal pleasure to be able to write in honour of Avery. I started to work for him as a medical registrar on Tuesday April 4th 1956. How am I so certain of the date? My only son was born on that day and Tuesday morning being the time for an endoscopy session I was experiencing my first glance down a rigid gastroscope whilst my wife, having been admitted to hospital the previous Saturday, Easter Saturday, was having an even more traumatic time with our first born. Hearing of my predicament Avery despatched me to my wife's bedside where some hours and a caesarian section later the urgent problem was solved. Quite a start!

Avery's interest in and exceptional experience of the problems of gastrointestinal bleeding is the subject of many important papers [Avery Jones, 1939, 1947(a), 1947(b), 1956, 1969]. The fundamental contributions that he made are now accepted as an integral part of the care of the patient with gastrointestinal bleeding. Perhaps the fact that so many contributions were made by Avery and his team at the Central Middlesex Hospital may be lost on more junior staff and students of today. This is however precisely what has happened. Perhaps this is best realized by a consideration of the way in which we handle patients with intestinal bleeding now, compared with current practice in the 1930s when Avery was beginning his clinical career. Nowadays we base our treatment on adequate blood transfusion, early surgery when it is required, adequate oral nutrition as soon as possible, avoidance of dehydration and rapid ambulation. Blood transfusion by drip was not available until 1935 (Marriott and Kekwick, 1935); surgery of serious bleeding had a very high mortality (about 30\%) (Finsterer, 1939; Gordon Taylor, 1937), and the treatment consisted of complete immobilization and gastric 'rest'. Thus patients were confined rigidly to bed for weeks on end. They were starved and only a much reduced fluid intake was allowed. Thirst and restlessness were combated with large doses of morphine. Ice to suck and an ice bag on the abdomen completed the torture. The unfortunate victim was not allowed to move at all from his bed for 2 weeks and eventually in an uncomplicated 3 case, much weaker and many pounds lighter, he or she escaped from hospital 6-10 weeks later. One can imagine the anguish of the patient with $ठ$ recurrent gastrointestinal bleeding who having remained on this strict regime then rebled and 8 was made to go back to square one and repeat the ? whole weakening process. It is perhaps surprising that the mortality was so low. Though numbers $Z$ were small most series (Cullinan and Price, 1932; Chiesman, 1932) quoted a mortality between 4 and $20 \%$, and usually 5-10\% (Bulmer, 1927)-but the severity of bleeding in these cases is largely unre corded.

Avery was particularly interested in the precis cause of death in patients who died following admission with gastrointestinal bleeding. In a paper (Avery Jones, 1939) written at Bart's and published $\overline{0}$ when Avery worked on the Professorial Medical Unit there under Professor Leslie Witts he described $\mathbb{D}$ details of 39 fatal cases. Eighteen of that 39 showed no evidence of continuing bleeding at autopsy, neither were the patients particularly elderly, feeble or anaemic (five were in fact less than 50 years of age). Estimation of blood and cerebrospinal fluid (CSF) urea showed that there was commonly $\exists$ a gross elevation which ranged from $272-860 \mathrm{mg} / \div$ $100 \mathrm{ml}(45-143 \mathrm{mmol} / \mathrm{l})$. In other words uraemia seemed to be a major reason for the fatalities and Avery was quick to realize that this was the result of pre-renal azotaemia. The patients who died in this o way had been clinically dehydrated - the very limited fluid intake allowed these patients in order to 0 obtain 'gastric rest' in no way kept pace with their urinary output. Dehydration and shrinkage of the or plasma volume led to poor renal perfusion. Now N clinicians might perhaps be loathe to attribute urea N levels of this magnitude to an entirely pre-renal $\omega$ cause. There can be no doubt that uraemia was a major cause of death and this highlighted the $\stackrel{0}{\odot}$ extremely unsatisfactory way in which the treatment $\stackrel{\Phi}{\rightarrow}$ of patients with gastrointestinal bleeding was conducted. 
Gastrointestinal bleeding at Central Middlesex Hospital

With the move to the Central Middlesex Hospital in 1940 there now came an opportunity to collect accurate data relating to a series of patients with gastrointestinal bleeding. This major district hospital had and still has a large intake of acutely ill patients. All patients with gastrointestinal bleeding were coded, and where possible the cause of that bleeding was ascertained. Large numbers of patients with this problem were attracted to the hospital. By 1947 (Avery Jones, 1947a, b) 687 patients with gastrointestinal bleeding had been personally treated by Avery. In 1956 this figure had risen to over 2000 (Avery Jones, 1956); by 1969 it was over 4000 (Avery Jones, 1969), and by the time he retired from the Central Middlesex in 1973 it was about 5000. Such numbers have not been recorded by any other centre, and Avery's data remain today as a unique testimony to this very special expertise. One can imagine the reaction of members of the American Gastroenterological Association at Atlantic City in 1956 (Avery Jones, 1956) when Avery gave their first memorial lecture-they must have been staggered by the enormity of his personal series. Such experience in America was and is unusual. It was not however just a matter of collecting numbers. Avery with his assistant Barbara White was the first to try and divide patients into causative groups so that an accurate prognosis of the individual conditions under consideration and the effects of factors like age and sex could be ascertained. This had not been done before; previous experience was based on small series only and no attempt had been made to classify them in relation to the cause of bleeding. Avery's series was therefore both extensive and special. From the very first he used a simple classification and he stuck to it. As his major interest was peptic ulcer he made certain that clear details of his ulcer group formed the basis of the data bank.

In order to be able to diagnose peptic ulcer and of course the other causes of gastrointestinal bleeding he had to be certain of excellence in diagnostic technique. It was therefore practice at the Central Middlesex Hospital as soon as the acute phase of bleeding was over to refer patients to the radiological department for a barium meal examination. All of those who had no radiological evidence of a lesion causing bleeding were then considered for gastroscopy. Avery pioneered this investigation in this country and was able to show that it could be carried out under sedation and local anaesthesia with few problems (Avery Jones et al., 1951). Using the narrower Wolf Schindler or the slightly more robust Hermon Taylor machine gastroscopy took place weekly. By 1956 when over 2000 intestinal bleeds had been seen and treated, 559 were barium negative and 303 of these were successfully gastroscoped. One must realise that the numbers of patients with X-ray negative intestinal bleeding would have been much greater-and the need for gastroscopy much higher -if the expertise of Dr Frank Pygott and his colleagues in the excellent Department of Radiology at the Central Middlesex had not been available.

The adoption of this system of investigation and the meticulous attention to the recording of data allowed:- 1 . the recognition and quantitation of the major causes of gastrointestinal bleeding; 2 . appreciation of the rarities; 3 . accurate evaluation of the mortality within the major groups and the assessment of the influence of factors such as age and sex on it; and 4. speculation about the natural history of acute gastric ulcers-a diagnosis not formerly possible except at laparotomy.

The major cause of bleeding in the Central Middlesex and indeed in other series was from peptic ulcer (Avery Jones, 1947a, 1947b, 1956, 1969). Four hundred and eleven of 687 in the period 1940-47 and 1764 of 2011 in the period up to 1956 were due to this cause. There were nearly twice as many chronic duodenal as chronic gastric ulcers, and patients in the acute (barium negative group) numbered about one third of the total ulcer group. Over one third of the patients within the acute group who were gastroscoped showed a site of bleeding. This was the first time that acute ulcers had been systematically viewed on gastroscopy, another area in which Avery was particularly interested (Avery Jones and King, 1953). He noted the nearly equal distribution of acute ulcers in the two sexes compared with a male predominance for chronic ulcers. There was commonly a short or non-existent history of dyspepsia before bleeding which could be severe and recurrent. The mortality for bleeding in this group was low and in any case the majority were young or middle aged. There were no important sequelae in women with an acute bleeding gastric ulcer, but nearly half of the male patients had recurrent problems and further chronic ulceration.

The data related to mortality and the consequences of this for treatment were without doubt the most significant findings within the massive Central Middlesex series. The overall mortality for gastrointestinal bleeding from all ulcers was $7.8 \%$, rising from $2 \%$ in those under 45 years of age to $21 \%$ in those over 70. When one looked at the figures in patients bleeding from chronic ulcers the mortality for DU was $2 \%$ under the age of 60 and $23 \%$ over that age, whilst for chronic gastric ulcer the mortality was $14 \%$ under 60 years of age and $28 \%$ over 60 . The figures for the mortality from acute ulcers were $<1 \%$ under 60 and $4 \%$ over that age. Thus it could be seen that there was a rising mortality with age for bleeding 
from chronic ulcers-particularly gastric, but that bleeding from acute ulcers showed no such significant rise. This rising mortality with age in the chronic group has been verified many times since (Allen and Dykes, 1976; Bown et al., 1981; Coghill and Willocx, 1959) and was the reason why Avery decided to adopt a more aggressive approach by surgical means in some of the patients. He argued that with such a high mortality associated with advancing age and with the ever improving standards of surgery and anaesthesia there were probably some bad risk patients who might be saved by surgery. In his first 400 Central Middlesex cases there were only three who were referred for surgery and all died, but Avery persisted with his 'bias towards surgical treatment' and of the next seven operated patients six survived. Comparing the mortality of a highly non-surgical group of 1941-46 with a surgically orientated group in 1951-54 he was able to show that there was a fall in the mortality of gastric ulcer patients treated surgically under the age of 60 , but no real improvement in mortality of the surgically-treated group over this age. Neither was there a change in the mortality of the acute and the chronic duodenal ulcer groups. This illustrates the present predicament we find ourselves in (Allen and Dykes, 1976; Bown et al., 1981) concerning the patient with gastrointestinal bleeding: there comes a cut-off point where increasing use of surgery also leads to increasing mortality and morbidity from age and its post-operative complications. Avery and his surgical colleagues showed us the way forward with the surgical therapy of severe bleeding, but as we know to our cost each individual candidate for surgery is a problem unto itself. At least from his work we learnt the danger signs in any particular case.

Excellent data were also obtained on the problem of re-bleeding. In the 1940-47 series (Avery Jones, 1947a, b) 110 patients-about a sixth-re-bled. The effects on the mortality were clear cut: $48 \%$ of patients re-bleeding from chronic gastric ulcer and $35 \%$ of those with re-bleeding chronic duodenal ulcer died. There was no major change in mortality from re-bleeding from acute ulcers. This dramatic increase in mortality with continued bleeding has since been repeatedly verified (Jones et al., 1973; Schiller, Truelove and Williams, 1970) and thus continued bleeding was added along with age and chronic ulceration to the list of danger signs and likely indications for surgical intervention which then and since have served as important guides to attendant clinicians.

Apart from pointing the way to surgery for the very ill patient Avery was of course interested too in the routine care of patients with bleeding of any severity. He was a firm advocate of the principles of Meulengracht (1935) presumably because of his very unfortunate experiences relating to the dehydrating and weakening treatment previously advocated. Me ulengracht spoke at the 1939 meeting of the B.M.A at Aberdeen (Meulengracht, 1939) and presented his? remarkable statistics obtained when using a method of early feeding. In 491 patients who had bled and흐. were treated in his unit in Copenhagen only 105 patients died-a fraction of the normal mortality. NO doubt many of Meulengracht's patients had blecw pretty minimally, but the results were impressive. In fact the more liberal approach was first used by Lenhartz (quoted by Haberman, 1906), and in this country by Spriggs (1909) at St George's Hospital but his contribution was forgotten. There is no doub? that the Meulengracht approach made a deep im 3 pression on Avery and his colleague Leslie Witts. They rightly argued that starvation and dehydration killed and that any physician could duplicate Meulengracht's apparently safe and commonsensèapproach, and, hopefully, his results.

The move to liberalize the background therapy of the patient with gastrointestinal bleeding, the detection of its cause, and assessment for surgery broughz about by more skilful radiology and endoscopy anç clinical care and the increased recognition of the danger signals meant increasing co-operation be tween physicians, surgeons, radiologists, dieticiafs and nursing staff. It served as an initiating stimulus the founding of a gastroenterology unit where patients' problems were similar-including of cou $\vec{乛} 8$ gastrointestinal bleeding-but where surgeons and physicians were co-operating fully, monitoring the patients' changing conditions and employing conser vative or surgical therapy according to previousl ${ }_{\mathbb{B}}^{\mathbb{D}}$ defined criteria. Avery thus made his most impor $\overrightarrow{\vec{P}}$ tant contribution in encouraging combined medical $\frac{\text { 일 }}{3}$ surgical liaison in patient care, the essence of good present-day gastroenterological practice (see Sircus: 1984, this issue, p. 725).

It is worthwhile now considering the changes in therapy, diagnosis and cause of intestinal bleeding: that have occurred since Avery's retirement from the NHS and to assess his contribution in relation to modern clinical practice and endeavour.

\section{Recent developments in gastrointestinal bleeding}

\section{The patients-have they changed?}

There is general agreement that Avery's warnings about the dangerous combination of old age and chronic intestinal bleeding were most timely. In fact the numbers of elderly patients with gastrointestinaf bleeding continue to increase and seem out of proportion even to the general increase in age subjects in the population (Allen and Dykes, 1976 Johnston et al., 1973). No doubt this is why our mortality for gastro-intestinal bleeding is no differen 5 
-and in some cases worse than Avery's (Schiller et al., 1970; Johnston et al., 1973; Bown et al., 1981). The elderly patient with bleeding tends not to stop bleeding and responds in a predictable way to surgery. Increased diagnostic accuracy has not been rewarded by lessening mortality (Dronfield, Ferguson and Mclllmurray, 1977).

\section{Newer investigations - have they helped?}

This is where there has been an obvious major breakthrough. Upper gastrointestinal endoscopy now allows a careful inspection of oesophagus, stomach and duodenum, and provided it is done within 24 hours of bleeding has a $90 \%$ chance of making a diagnosis (Thomas, Cotton and Clark, 1978). The field of vision available in the stomach with the rigid gastroscope was very much restricted. The fundus and of course the duodenum were blind areas, and the identification of duodenal ulceration was entirely a radiological exercise. Acute duodenal ulceration was therefore not diagnosable at all, neither were lesions like the Mallory Weiss syndrome. Excellent as the radiology available to Avery was, it was also of the single contrast type. Perhaps spurred on by the major advances in endoscopy, radiological techniques have also improved very considerably, and double contrast barium studies particularly of the stomach and duodenum have allowed the identification of single and multiple erosions (Fraser, 1978) and have a total diagnostic success rate in upper gastrointestinal bleeding of over $80 \%$.

There has also been advancement in the application of angiography and scintiscanning to the intestinal blood vessels, not only in the demonstration of sites of bleeding but also detection of its cause-notably when this is associated with angiodysplasia (Athanasoulis, Waltman and Novellin, 1976; Welch, Athanasoulis and Galdabini, 1978).

Apart from these techniques other refinements have led to adoption of procedures such as central venous catheterization-certainly a valuable way of assessing transfusion requirements and detection of the early signs of re-bleeding. Perhaps it was overenthusiastically used when introduced and certainly most patients do not need this extra method of monitoring. One of the best papers on this technique was from Tim Northfield when he was registrar with Avery (Northfield, 1970).

\section{New causes of intestinal bleeding?}

Pre-eminent here has been angiodysplasia of the colon. Rarely reported before 1960 and principally in the right colon and in elderly patients (Wolff, Grossman and Shinya, 1977), it is now known to occur in young patients too, and to affect other parts of the colon (Miller et al., 1979) and the stomach
(Roberts, Gold and Routt, 1981). There is too a recognized association with stenotic aortic valve disease (Gelfand et al., 1979). Diagnosis is by colonoscopy and angiography, both of which techniques were not available to Avery, at least not in the 1940s, 50s and early 60s. Perhaps some cases were to be found in those reported by him with intestinal bleeding without a known cause (Avery Jones, Read and Stubbe, 1959) where nearly one fifth had a cause of bleeding discovered later-usually an ulcer. With the identification of angiodysplasia and the prominent part played by angiography in its detection there has also been wider recognition of other vascular abnormalities, namely: haemangioma, arterio-venous anastomoses and hereditary haemorrhagic telangiectasia which were also recognised in the Central Middlesex series. More recently recognized are abnormal vessels related to chronic liver disease (van Vliet et al., 1978) and Delafeux's disease (Mortensen et al., 1983) where there are submucosal arterial malformations. This latter is a recognized cause of massive haematemesis.

The problem of aspirin-induced bleeding interested Avery as a cause of bleeding and was supported by work from his Unit (Alvarez and Summerskill, 1958). It has since run into some problems based on the questionable adequacy of controls in some of the papers and the fact that a general increase in analgesic taking may be a feature of the patient with gastrointestinal bleeding (Langman, 1974).

Interestingly enough acute erosive gastritis was not a major disorder that featured in Avery's data, indeed in the first 2000 he said 'the diagnosis has been firmly made in a few patients only'. This in fact may be a new disease in that it is particularly found in the intensive care situation where head injury, burns, surgery sepsis and fulminant hepatic failure are important causes, as are alcohol and drugs. The mortality in this group for obvious reasons is high, and treatment is usually conservative with blood replacement, antacids or, better, cimetidine. The latter has resulted in a decreased mortality particularly in the situation complicating liver failure (McDougall, Bailey and Williams, 1977).

\section{New approaches to therapy-have these helped?}

(a) Drugs. There has been continuing interest in trying to find a drug which would stop alimentary bleeding, particularly when one remembers the alarming mortality of continuing bleeding. The discovery of the $\mathrm{H}_{2}$ blockers, the introduction of the first one without major side effects - cimetidine-and the successful early trials in the production of healing of both gastric and duodenal ulcers led to early optimism that cimetidine and subsequent $\mathrm{H}_{2}$ blockers would be valuable agents in patients with intestinal 
bleeding. In the event they have proved disappointing in patients with bleeding chronic ulcers (Siddio et al., 1979; La Brooy et al., 1979), though at least one group have found some advantage in the patient with bleeding gastric ulcer (Hoare et al., 1979). Although they are given to the patient who bleeds from a chronic ulcer, they are given to heal the ulcer and not to stop the bleeding.

As with other stress situations, gastrointestinal bleeding is associated with increased fibrinolytic activity in the blood and this could potentially exacerbate the conditions. However, results of the use of antifibrinolytic agents by mouth (Cormack et al., 1973) have shown some but not major advantages in respect of transfusion requirements and emergency surgery, so that this therapy is rarely used. Similarly, vasopressin (Johnson et al., 1977) and its analogues -though widely used and of proven efficiency in patients with bleeding varices-have generally been disappointing in the treatment of other causes of gastrointestinal bleeding: the benefit seems temporary and major bleeding or re-bleeding do not usually respond. Antacids are unlikely to be effective except perhaps in patients with acute haemorrhagic gastritis, and in any case they are less potent than $\mathrm{H}_{2}$ blockers.

Somatostatin produces cessation of gastric, pancreatic and biliary flow, and there is diminution of portal blood flow (Gomez-Pan et al., 1975). A beneficial effect was seen too, experimentally in rats in whom the incidence of stress ulcer following immobilization and hypoxia was decreased (Mattes, Lauterback and Raptis, 1976). Portal vein blood flow is reduced by somatostatin (Jaspan et al., 1979), and in a randomized controlled trial with 10 pairs of patients with bleeding peptic ulcer it was more effective than cimetidine (which is not effective) (Kayasseh et al., 1980). Unfortunately, too, it has to be given intravenously for up to 5 days. This could delay an important decision related to emergency surgery, and elderly patients could be significantly less able to stand up to surgery if it were ineffective. Much bigger numbers are required and in particular the important problem of an effect in recurrent bleeding needs careful and extensive trials.

(b) Surgery. There have been, of course, improvements in surgical and anaesthetic techniques which should have been associated with an improved mortality. Simpler operations have been used-partial gastrectomy has been replaced by suture and truncal vagotomy with pyloroplasty for bleeding duodenal ulcer. Gastric ulcer can also be more simply treated by wedge resection and again some surgeons would perform a truncal vagotomy and pyloroplasty as well. Unfortunately pulmonary embolism, cardiovascular complications, particularly congestive failure, and pulmonary infection have more than made up for the improvement in technology. This has led to claims both for earlier and $C$. simpler surgery on the one hand (Schiller et al., 1970) $\vec{F}$ and more conservative therapy on the other (Allen $\stackrel{5}{+}$ and Dykes, 1976).

(c) Other methods of treatment. We have success- $\frac{\bar{\phi}}{\bar{\phi}}$

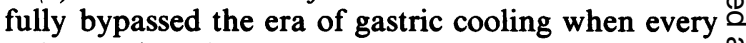
unit purchased at some expense a gastric cooling कै unit. Not only was this uncomfortable for the patient, $\vec{\circ}$ but it was subsequently shown to be useless (Rodgers, Older and Stabler, 1966) and the mortality was $\vec{\omega}$ generally increased even when bleeding stopped because of the dangerous complications, particularlyo aspiration pneumonia.

No doubt we are being a little more circumspect with the various types of manipulative endoscopy. $\checkmark \checkmark$ Sclerotherapy does seem to be an advance in the treatment of varices (Terblanche et al., 1979; Wes- $/$ \% taby, McDougall and Williams, 1983) but it has had its protagonists over the past 20 years and is hardly a new technique-more a forgotten one.

Laser photocoagulation: there has been an increasing interest in the application of this technique to the $\Phi$ problem of gastrointestinal bleeding. There is evi- $\bar{z}$ dence in randomized trials that the Nd YAG laser $\stackrel{\mathbb{N}}{-}$ can stop bleeding where there is an exposed vessel $\overrightarrow{0}$ an ulcer base (Swain et al., 1983). The re-bleedinf incidence was five times higher in the control compared with the laser group and there was $\vec{a}$ reduced requirement for surgery and a decreased mortality. This specialized treatment could be helpful in dealing with the dangerous elderly chronic ulcer group that Avery identified.

Are there any better predictors of the outcome of gastrointestinal bleeding?

Nearly all series reported strongly agree with $\stackrel{\bar{\partial}}{\partial}$ Avery's findings that age, the cause of bleeding and 3 the presence of re-bleeding are the strongest indica- $\dot{\sigma}$ tors of likely outcome. Certainly these are the factors we rely on in everyday clinical work. Others have $\delta$ tried to add-but never subtract from-this list. Thus one group felt that a short dyspeptic history (Coghill 응 and Willocx, 1959) in relation to chronic peptic ulcer $>$ was important, and this group also emphasized the importance of complicating heart failure. Another $\mathrm{N}$ group (Morgan et al., 1977) using a computer study (r found being teetotal a risk factor, and not taking $N$ drugs another-simply because acute ulceration with $N_{\omega}$ a good outcome is usually a feature of these two activities. A high volume of blood transfused seems $a_{0}$

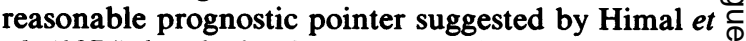
al. (1974) but lack of a pre-operative diagnosis also $\stackrel{9}{?}$ recorded by this group has not been sustained as a 0 prognostic pointer. 
Mention must also be made of the value of endoscopy in determining which patients are likely to re-bleed. Thus active bleeding, the presence of fresh clots or an eroded vessel or darkened slough at endoscopy are features to suggest the possibility of re-bleeding and its consequent dangers (Foster, Miloszewski and Losowsky, 1978).

One is inclined to suggest on looking at the 'advances' that there are very few areas where significant changes have been made, and where these have occurred they have been due to improved technology only. Improved technology is in any case a direct result of the passage of time. Even here one must admit that the results-by which our worth is measured by our patients-have not been improved by most of the technology that has been introduced. One is forced to conclude that Avery said it all-or nearly all, and that the present day management of gastrointestinal haemorrhage has progressed very little since his contributions. A remarkable result, Avery-and may we all thank you for putting us so certainly on the right clinical pathways.

\section{References}

ALLEN, R. \& DYKes, P. (1976) A study of factors influencing mortality rates for gastrointestinal haemorrhage. Quarterly Journal of Medicine, 45, 533.

AlvareZ, A.S. \& SummersKILL, W.H.J. (1958) Gastrointestinal haemorrhage and salicylates. Lancet, i, 920.

Athanasoulis, C.A., Waltman, A.C. \& Novellin, R.A. (1976) Angiography: its contribution to the emergency management of gastrointestinal haemorrhage. Radiologic Clinics of North America, 14, 265.

Bown, S.G., SALMON, P.R., Brown, P. \& ReAD, A.E. (1981) Upper gastrointestinal haemorrhage. Journal of the Royal College of Physicians of London, 15, 265.

BULMER, E. (1927) The mortality from haematemesis. Lancet, ii, 168.

CHIESMAN, W.E. (1932) Mortality of severe haemorrhage from peptic ulcers. Lancet, ii, 722.

CoGHILL, N.F. \& WiLLOCX, R.G. (1959) Factors in the prognosis of bleeding chronic gastric and duodenal ulcers. Quarterly Journal of Medicine, 29, 575.

Cormack, F., Chakrabarti, R.R., Jouhar, A.J. \& Fearnley, G.R. (1973) Tranexamic acid in upper gastrointestinal haemorrhage. Lancet, i, 1207.

Cullinan, E.R. \& Price, R.K. (1932) Haematemesis following peptic ulceration. St Bartholomew's Hospital Reports, 65, 185.

Dronfield, M.W., Ferguson, R. \& MCIllmurRay, M.B. (1977) A prospective randomised study of endoscopy and radiology in acute upper gastrointestinal tract bleeding. Lancet, i, 1167.

FINSTERER, H. (1939) Surgical treatment of acute profuse gastric haemorrhage. Surgery, Gynecology and Obstetrics, 69, 291.

FosTeR, D.N., MILoszewSKI, K.J.A. \& LosowSKY, M.S. (1978) Stigmata of recent haemorrhage in diagnosis and prognosis of upper gastrointestinal bleeding. British Medical Journal, 1, 1173.

FRASER, G.M. (1978) The double contrast barium meal in patients with acute upper gastrointestinal bleeding. Clinical Radiology, 29, 625.

Gelfand, M.L., Cohen, T., ACKert, J.J. Ambos, M. \& Mayadag, M. (1979) Gastrointestinal bleeding in aortic stenosis. American Journal of Gastroenterology, 71, 30.

Gomez-Pan, Albinus, M., Reed, J.D., Shaw, B., Hall, R., Besser, G.M., CoY, D.H., KASTIN, A.J. \& Schally (1975) Direct inhibition of gastric acid and pepsin secretion by growth hormone release inhibiting hormone in cats. Lancet, $\mathbf{i}, \mathbf{8 8 8}$.

GORDON TAYLOR, G. (1937) The problem of the bleeding peptic ulcer. British Journal of Surgery, 25, 403.

HABERMAN, J.V. (1906) The Lenhartz treatment of gastric ulcer at the Eppendorfer Krankenhaus, Hamburg. Lancet, ii, 25.

Himal, H.S., Watson, W.W., Jones, C.W., Miller, L. \& MACLEAN, L.D. (1974) The management of upper gastrointestinal haemorrhage. Annals of Surgery, 179, 489.

Hoare, A.M., BRadBY, G.V.H., Hawkins, C.F., Kang J.Y. \& DYKES, P.W. (1979) Cimetidine in bleeding peptic ulcer. Lancet, ii, 671 .

Jaspan, J., Polansky, K., Lewis, M. \& Moosa, A.R. (1979) Reduction in portal vein blood flow by somatostatin. Diabetes, 28 , 888.

JohnSON, W.C., WildRich, W.C., ANSEll, J.E., Robbins, A.H. \& NABSETH, D.C. (1977) Control of bleeding varices by vasopressin. Annals of Surgery, 186, 369.

JONES, F. AVERY (1939) Haematemesis and melaena. Observations on salt and water requirements. British Medical Journal, 2, 332.

JONES, F. AVERY (1947) Haematemesis and melaena. With special reference to bleeding peptic ulcer. British Medical Journal, 2, 441.

JONES, F. AVERY (1947) Haematemesis and melaena. With special reference to bleeding peptic ulcer. British Medical Journal, 2, 477.

JONES, F. AVERY (1956) Haematemesis and melaena. With special reference to causation and to factors influencing the mortality from bleeding peptic ulcers. Gastroenterology, 30, 116.

JoNes, F. AVERY (1969) Problems of alimentary bleeding. British Medical Journal, 2, 267.

JONES, F. AVERY, DOLl, R., Fletcher, C. \& RODGERS, H.W. (1951) The risks of gastroscopy. Lancet, $\mathrm{i}, 647$

JONES, F. AVERY \& KING, W.E. (1953) Study of acute gastric ulcers causing haemorrhage. Australasian Annals of Medicine, 2, 179.

Jones, F. AVery, ReAD, A.E. \& STUBbe, J.L.S. (1959) Alimentary bleeding of obscure origin - a follow-up study and commentary. British Medical Journal, 1, 1138.

Jones, P.K., Johnston, S.J., MCEwan, A.B., KYLE, J. \& NeEdham, C.D. (1973) Further haemorrhage after admission to hospital for gastrointestinal haemorrhage. British Medical Journal, 3, 660.

Johnston, S.J., Jones, P.K., KYLE, J. \& · NeEdham, C.D. (1973) Epidemiology and cause of gastrointestinal haemorrhage in North East Scotland. British Medical Journal, 3, 655.

KaYasseh, L., Keller, U., Gyr, K., STadler, G.A. \& Wall, M (1980) Somatostatin and cimetidine in peptic ulcer haemorrhage. Lancet, i, 844.

La Brooy, S.J., Misiewicz, J.J., Edward, J., SMith, P.M., Haggie, S.J., Libman, L., SARNer, M., Wyllie, J.H., Croker, J. \& CotTon, P. (1979) Controlled trial of cimetidine in acute upper gastrointestinal bleeding. Gut, 20, 892.

LANGMAN, M.J.S. (1974) Aspirin is not a major cause of acute gastrointestinal bleeding. In: INGELFINGER, F.J., EBERT, R.V., FINLAND, R.V. et al. Eds. Controversy in Internal Medicine. Philadelphia, Saunders, p. 493.

MCDougall, B.R.D., Bailey, R.J. \& Williams, R. (1977) $\mathrm{H}_{2}$ receptor antagonists and antacids in the prevention of acute gastrointestinal haemorrhage in fulminant hepatic failure. Lancet, i, 617 .

MARRIOTT, H.L. \& KeKWICK, A. (1935) Continuous drip blood transfusion. Lancet, i, 977.

MatTes, P., LaUterbach, H.H. \& RaPTIS, S. (1976) Prevention of stress ulcer by somatostatin in rats. Langenbecks Archiv für klinische Chirurgie, 341, 297.

MeUlengRACHT, E. (1935) Treatment of haematemesis and melaena with food. The mortality. Lancet, ii, 1220.

MeUlengraCHT, E. (1939) The medical treatment of peptic ulcer and its complications. British Medical Journal, 2, 321.

MilleR, K.D., TUtTon, R.H., Bell, K.A. \& Simon, B.K. (1979) Angiodysplasia of the colon. Radiology, 132, 309.

MoRgan, A.G., MCAdaM, W.A.F., WALMSLEy, G.L., Jessor, A., Horrocks, J.C. \& DE DOMBAL, F.T. (1977) Clinical findings, early endoscopy and multivariate analysis in patients bleeding 
from the upper gastrointestinal tract. British Medical Journal, 3, 237.

MoRTEnSEn, N.J. MCC., Mountford, R.A., Davies, J.E. \& JeANS, W.D. (1983) Delafeux's Disease: a distinctive arteriovenous malformation causing massive gastric haemorrhage. British Journal of Surgery, 80, 76 .

NORTHFIELD, T.C. (1970) Central venous pressure in clinical management of acute gastrointestinal bleeding. Lancet, ii, 584 .

ROBERTS, L.K., GOLD, R.E. \& ROUTT, W.E. (1981) Gastric angiodysplasia. Radiology, 139, 355.

Rodgers, J.B., Older, T.M. \& Stabler, E.V. (1966) Gastric hypothermia. Arterial evaluation of its use in massive upper gastrointestinal bleeding. Annals of Surgery, 163, 667.

Schiller, K.F.R., Truelove, S.C. \& Williams, D.G. (1970) Haematemesis and melaena with special reference to factors influencing the outcome. British Medical Journal, 2, 7.

SidDiou, S.M.Z.A., Tildesley, G., PICKENS, P.T. \& MCNAY, R.A. (1979) Cimetidine in acute gastrointestinal bleeding. British Medical Journal, 1, 954.

SIRCUS, W. (1984) Medical-surgical collaboration in the practice of gastroenterology. Postgraduate Medical Journal, 60, 725.

SPRIGGS, E.I. (1909) Treatment of gastric ulcer by immediate feeding. British Medical Journal, 1, 825.

Swain, C.P., Bown, S.G., Salmon, P.R., Kirkham, J.S. \& NorThFIELD, T.C. (1983) Controlled trial of Nd YAG laser photocoagu- lation in bleeding peptic ulcers. In Abstracts of the 44th Ann. Gen Meeting of the British Soc. of Gastroenterology, p. 20.

Terblanche, J., Northover, J.M.A., Bornmann, P. Kahn, D., Silber, W., Barbezat, G., Sellars, S., Campbell, J.A.H. \& SAUNDERS, S.J. (1979) A prospective controlled trial of sclerotherapy in long term management of patients after oesophagea? variceal bleeding. Surgery, Gynecology and Obstetrics, 148, 323. 므 Thomas, G.E., CotTon, P.B. \& ClaRK, C.G. (1978) Survey ofōs management in acute upper gastrointestinal haemorrhage. Journa君 of the Royal Society of Medicine, 73, 90.

VAN VLIET, A.C.M., TEN KATE, F.J.W., DEES, J. \& VAN BLANKEN STEIN, M. (1978) Abnormal blood vessels of the prepyloric antrum in cirrhosis of the liver as a cause of chronic gastrointestinab bleeding. Endoscopy, 10, 89.

Welch, C.E., Athanasoulis, C.A. \& Galdabini, J.J. (1978) Haemorrhage from the large bowel with special reference to angiodysplasia and diverticular disease. World Journal of Surgeryg $2,73$.

WeSTABY, D., MCDougall, B.R.D. \& Williams, R. (1983) Im provement in long term survival with injection sclerotherapy: fina $B$ analysis of a controlled trial. Abstracts of the 18th meeting of the European Association for the Study of the Liver, p. 34.

WolfF, W.I., Grossman, M.B. \& ShINYA, H. (1977) Angiodysplasia of the colon: diagnosis and treatment. Gastroenterology, $72 \mathrm{~g}$ 329. 